\title{
Application of Drying Model to Determine Extraction Behaviours on Peanut Skin Oil Recovery by Supercritical Carbon Dioxide-Ethanol
}

\author{
Nicky Rahmana Putraa,*, Dwila Nur Rizkiyaha, Ahmad Hazim \\ Abdul Aziza, Zuhaili Idham ${ }^{a}$, Jumakir Jumakirb, Waluyo \\ Waluyoc, Mohd Azizi Che Yunus ${ }^{a, *}$
}

aCentre of Lipid Engineering and Advanced Research (CLEAR), Ibnu Sina Institute for Scientific and Industrial Research, Universiti Teknologi Malaysia, 81310, UTM Johor Bahru, Malaysia; ${ }^{b}$ Assesment Institute of Agricultural Technology (AIAT) Jambi, Indonesia; ${ }^{\mathrm{C}}$ Assesment Institute of Agricultural Technology (AIAT) Palembang, Indonesia

Abstract The main objective of this study was to determine the mass transfer for extraction of peanut (Arachis hypogea) skin by using drying models as alternatives extraction models. The mass transfer was measured at the pressure ranging from $10 \mathrm{MPa}$ to $30 \mathrm{MPa}$, temperature of 40 ${ }^{\circ} \mathrm{C}$ to $70{ }^{\circ} \mathrm{C}$, and rate of modifier $0.075 \mathrm{~mL} / \mathrm{min}$ to $0.225 \mathrm{~mL} / \mathrm{min}$. The Lewis, Page, Peleg, Henderson and Pabis, and Avhad and Macetti as drying models were modified to illustrate the extraction process and to transform as alternative empirical models. An average absolute relative deviation percentage (AARD\%) of Lewis, Page, Peleg, Henderson - Pabis, and Avhad-Macetti was $9.52 \%, 4.67 \%, 19.41 \%, 0.26 \%$, and $0.04 \%$. Avhad and Macetti model offered the best fitting between experimental data and modelling data. The results showed that drying model was applicable to correlate the experimental data of extraction process due to low percentage of error and high coefficient determination.

Keywords: Arachis hypogea; Mass transfer; Drying models; Supercritical carbon dioxide

\section{${ }^{*}$ For correspondence:}

rpnicky2@graduate.utm.my and azizi@cheme.utm.my

Received: 13 Aug 2020 Accepted: 1 Feb 2021

(C) Copyright Putra. This article is distributed under the terms of the Creative Commons Attribution License, which permits unrestricted use and redistribution provided that the original author and source are credited.

\section{Introduction}

Peanut skin as a waste of peanut butter industries contain catechin, anthocyanidins, oleic acid, procyanidins, and epicatechin [1-6]. Most of the bioactive compounds have been associated with reduced risk of cardiovascular diseases and cancers [1]. Furthermore, the exploitation of peanut skins as a renewable raw material is needed for antioxidant compounds because it provides protection against human health and enhancement of the sustainable environment [7].

Supercritical carbon dioxide $\left(\mathrm{SC}-\mathrm{CO}_{2}\right)$ extraction is a green and suitable alternative extraction technology [8]. The $\mathrm{SC}-\mathrm{CO}_{2}$ offers several advantages such as inexpensive and non-toxic solvent. However, SC$\mathrm{CO}_{2}$ has a limitation on the target compounds, where it is only suitable for the extraction of nonpolar compounds [9]. Hence, the modification of $\mathrm{SC}-\mathrm{CO}_{2}$ is needed to extract polar compounds. This drawback can be overcome by the addition of ethanol to enhance the polarity of $\mathrm{SC}-\mathrm{CO}_{2}$ [10]. Ethanol as a modifier is safer in terms of toxicity compared with other solvents such as methanol and ethylene glycol [11]. Other applications using $\mathrm{SC}-\mathrm{CO}_{2}$ approach include the extraction of oils from avocado [12], 
Pithecellobium jiringan seeds [13], tomato skins [14], rosehips [15], and mango ginger [16].

Mass transfer models are important at several stages in the $\mathrm{SC}-\mathrm{CO}_{2}$ extraction in terms of feasibility evaluations, process design, equipment sizing, and establishment of optimum operating conditions [17]. There are two types of modelling on the $\mathrm{SC}-\mathrm{CO}_{2}$ extraction such as kinetic and empirical models. The kinetic model is more focused on the specific mass-transfer process, but the empirical model focus on the general mass transfer model. The drying model has parabolic or exponential curves that are similar to the $\mathrm{SC}-\mathrm{CO}_{2}$ extraction curve [18]. Therefore, the modification of drying models is suitable as empirical $\mathrm{SC}-\mathrm{CO}_{2}$ extraction models. The models can correlate and predict the mass transfer between solvents and solutes [17].

There are various modelling in the drying process, but Lewis [19], Page [20], Peleg [21], Henderson and Pabis [22], and Avhad Macetti [23] models were modified and developed to be applied due to less adjustable. Hence, the development of drying model can easily fit the experimental data. Furthermore, the drying model can be applied as an alternative empirical model to describe the extraction process behaviours.

The objectives of this study were to determine the mass transfer for extraction of Arachis hypogaea skin oil using modified supercritical carbon dioxide by modifying the drying models. Another objective was to determine the best correlation between models and experimental data.

\section{Materials and methods}

\section{Sample preparations}

Peanut (Arachis hypogea) skins was purchased from G-Tachfood Industries Sdn Bhd, Johor Bahru, Malaysia. The skins were dried in an oven at $60{ }^{\circ} \mathrm{C}$ for 4 hours and blended into powder, sieved to 425 $\mu \mathrm{m}$ to obtain the mean of particle size, and placed in a freezer under $-20^{\circ} \mathrm{C}$ prior to use.

\section{Chemical preparations}

Liquid carbon dioxide (99\% purity) was used in the supercritical extraction apparatus purchased from Kras Instrument, Johor Bahru, Malaysia Food grade of ethanol (99.86\%) was purchased from Fisher Scientific Chemical (Loughborough, UK) and Merck (Darmstadt, Germany).

\section{Supercritical carbon dioxide extraction assisted by ethanol}

Liquid $\mathrm{CO}_{2}$ and ethanol as modifier were continuously pumped into the system with at a flow rate of 3 $\mathrm{mL} / \mathrm{min}$. The extraction was conducted at pressure of 10 to $30 \mathrm{MPa}$; temperature of 40 to $70{ }^{\circ} \mathrm{C}$; the rate of the modifier of 0.075 to $0.225 \mathrm{~mL} /$ minute and extraction time for $180 \mathrm{~min}$. Chiller temperature was set at $6{ }^{\circ} \mathrm{C}$ while the heater in the back-pressure regulator (Jasco BP 2080 Plus Automated BPR) was set at $50{ }^{\circ} \mathrm{C}$. An amount of $5 \pm 0.005 \mathrm{~g}$ of peanut skins were placed into an extraction vessel. Then, the extracted oil was collected and it was recorded every 30 minutes for 180 minutes. The extract collected was dried in an oven to evaporate the ethanol, before being stored at $4{ }^{\circ} \mathrm{C}$ to prevent any possible degradation.

\section{Calculation of peanut skins oil yield}

The oil yield ( $\mathrm{g}_{\text {extract }} / \mathrm{g}_{\text {sample}}$ ) was determined by using the following equation:

Oil yield $=\frac{\mathrm{m}_{\mathrm{e}}}{\mathrm{m}_{\mathrm{s}}} *(100 \%)$

Where $m_{e}$ is the total mass of the extracted oil in the collection vial $(\mathrm{g})$ and $\mathrm{m}_{\mathrm{s}}$ is the weight of the sample used (g). 


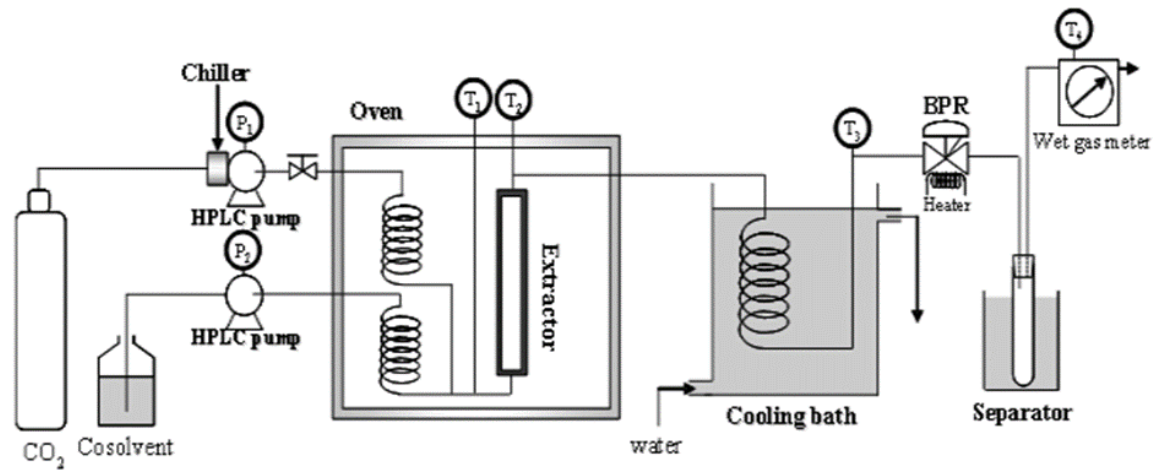

Figure 1. The schematic diagram of SFE unit

\section{Calculation of peanut skins oil ratio (PSOR)}

The calculation of peanut skins oil ratio (PSOR) was needed in every fraction of extraction process due to the calculation and determination of the mass transfer process. The calculation of peanut skin oil ratio was determined by using the following equation:

PSOR $=\frac{\mathrm{m}_{\mathrm{e}}}{\mathrm{m}_{\mathrm{t}}}$

Where $m_{e}$ is the total mass of the extracted oil and $m_{t}$ is the total weight of extracted oil yield $(\mathrm{g})$.

\section{Development of drying model to determine extraction behaviours}

Lewis, Page, Peleg, Henderson, and Pabis and Avhad, and Macetti model were generally used as adsorption and drying process model to determine kinetically mass transfer of water to air. Adsorption and drying process have a similar curve with modified $\mathrm{SC}-\mathrm{CO}_{2}$ in terms of a parabolic curve. Consequently, these models are suitable to be used for the determination of kinetic constant [18].

\section{Lewis model}

The Lewis model was easily solved by a solver due to one adjustable parameter [19]. The assumption of this model is a negligible internal resistance, indicative of no resistance to moisture movement from within the interior of the material out to the surface of the material [19]. Lewis model is an exponential and parabolic curve that is similar to the modified $\mathrm{SC}-\mathrm{CO}_{2}$ curve. Therefore, the Lewis model is suitable to determine the kinetic model of modified $\mathrm{SC}-\mathrm{CO}_{2}$ extraction [18]. However, a new modification of the Lewis model is needed to correlate the experimental data. The Lewis model is represented as:

$\mathrm{MR}=\exp \left(-\mathrm{k}_{\mathrm{l}} \mathrm{t}\right)$

The modification of the Lewis model is mentioned as follows:

PSOR $=1-\exp \left(-k_{l} t\right)$

Where $M R$ is the moisture ratio, PSRO is the peanut skins oil ratio and $k_{l}$ is the constant of the model following an Arrhenius expression and $t$ is time of extraction (sec).

\section{Henderson-Pabis model}

The Henderson-Pabis $(\mathrm{H}-\mathrm{P})$ model is also known as a bi-parametric exponential model. This model is 
the first term of a general series of Fick's second law solution. The slope of this model, coefficient $k_{h}$, is linked to the effective moisture diffusivity when the drying process takes place only in the falling rate period and liquid diffusion control process. The effective moisture diffusivity is similar to the diffusivity of $\mathrm{SC}-\mathrm{CO}_{2}$ to peanut skin oil. Therefore, the moisture ratio is substituted with peanut skin oil ratio. Henderson-Pabis Model is written as:

$M R=\operatorname{aexp}\left(-k_{h} t\right)$

The modification of Henderson and Pabis model is written as follows:

PSOR $=1-\operatorname{aexp}\left(-k_{h} t\right)$

Where $M R$ is the moisture ratio, PSRO is the peanut skins oil ratio. $a$ and $k_{h}$ are the constants of the model following an Arrehinius expression, and $t$ is the extraction time (sec) [22].

\section{Page model}

Lewis model was developed with the addition of two coefficient constants proposed by Page (1949). This model has produced good fits to characterize the drying of several agricultural products [23]. This model assumed that time is the big influence in the dying process. Therefore, time is one of the significant effects in the extraction process. Due to the similarity of parabolic curves between drying and extraction process, the assumption for development in the Page model is $N$ as the extraction time and $k_{p}$ as the diffusivity of solvents to solute. The Page model is written in the following form:

$M R=\exp \left(-k_{p} t\right)^{N}$

The modification of the Page model is written as follows:

PSOR $=1-\exp \left(-k_{p} t\right)^{N}$

Where $M R$ is the moisture ratio, PSRO is the peanut skins oil ratio. $k_{p}$ and $N$ are the constants of the model, $k_{p}$ follows an Arrhenius expression and $t$ is the extraction time (sec).

\section{Peleg model}

Moisture sorption process is described by Peleg model with the hyperbolic curve [21]. It is confirmed that the curve of the Peleg model was similar to $\mathrm{SC}-\mathrm{CO}_{2}$ extraction. Previous research shows that Peleg model has successfully described the kinetic extraction process [24-27]. Peleg model was fitted to experimental data from peanut skin oil. The equation of the Peleg model is described as follows:

PSOR $=\frac{a t}{k_{g}+t}(9)$

Where $M R$ is the moisture ratio, PSOR is the peanut skins oil ratio. $a$ and $k_{g}$ are the constant parameters of the Peleg model and $t$ is the time of extraction (sec). Furthermore, $k_{g}$ represents the solvation power of modified supercritical carbon dioxide as the solvent. Increasing the coefficient $k$ enhance the mass transfer process between the solvent and the solute.

\section{Avhad and Macetti model}

Avhad and Macetti model is combination of the Page model and the Henderson and Pabis model. This model assumed that resistance to mass transfer at the surface of a sample is negligible compared to the internal resistance of the sample, and the initial moisture content in the avocado seeds is high and 
uniformly distributed throughout the mass of the seed [23]. The curve of Avhad-Macetti model is a parabolic curve, which is similar to the extraction curve. The assumptions for development of this model are resistance to mass transfer at the surface is negligible compared to the internal resistance of the sample, and peanut skin oil in the peanut skins is high and uniformly distributed in the surface of the solute. The Avhad-Macetti model is written as:

$M R=\operatorname{aexp}\left(-k_{a} t\right)^{N}$

The development of this model can be written as:

PSOR $=1-\operatorname{aexp}\left(-k_{a} t\right)^{N}$

Where $M R$ is the moisture ratio, PSRO is the peanut skins oil ratio, $t$ is the extraction time (sec). $k_{a}, a$, and $N$ are constants of the model. $k_{a}$ follows an Arrhenius expression.

\section{Statistical analysis}

The statistical analysis is needed to determine a suitable fitted model based on the experimental data of peanut skin oil. The statistical analyses are the coefficient of determination $\left(\mathrm{R}^{2}\right)$ and average absolute relative deviation $(A A R D(\%))$.High coefficient of determination and low mean of absolute error indicated that the model is successfully fitted the experimental data [28]. The expressions for the coefficient of determination and average absolute relative deviation (AARD) are written as:

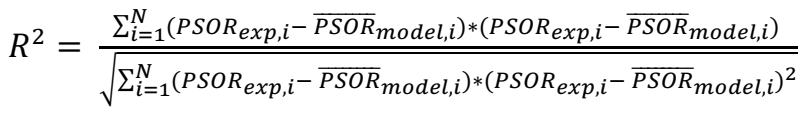

$$
\begin{aligned}
& \operatorname{AARD}(\%)=\frac{\sum_{i=1}^{N}\left(P S R O_{\text {exp }, i}-\overline{P S R O}_{\text {model }, i}\right)}{N}
\end{aligned}
$$

Where, $P S O R_{\text {exp }, i}$ is the $i$ th experimental dimensionless peanut skin oil ratio; $\overline{P S O R}_{\text {model, } i}$, is the $i$ th predicted dimensionless peanut skin oil ratio, and $N$ is the number of observations.

\section{Results and discussion}

The results of mathematical modelling are typically used in the design, planning and scaling up of chemical processes from laboratory to industrial scale [17]. The drying models can be characterized as an empirical model due to the evaluation of mass transfer extraction process [29]. The drying models can be used as an alternative mass transfer model due to the easily correlated the experimental data and have one or two adjustable parameters. Hence, the drying models can be called the first order models [30].

In order to minimize the error of the experiment, the moisture content and particle size were adjusted to $8.87 \%$ and $425 \mu \mathrm{m}$, respectively. High moisture content will inhibit $\mathrm{SC}-\mathrm{CO}_{2}$ to penetrate the peanut skin to carry out the extract [5]. In addition, the highest yield extract was $16.22 \%$ at 300 bar, $328 \mathrm{~K}$, with the rate of modifier was $0.15 \mathrm{~mL} / \mathrm{min}$. The lowest yield extract obtained was $2.01 \%$ at $10 \mathrm{MPa}, 70{ }^{\circ} \mathrm{C}$, with rate of modifier $0.075 \mathrm{~mL} / \mathrm{min}$ as shown in Table 1.

Table 1 reveals that the effect of pressure is very significant to enhance and encourage the peanut skin oil yield. This is due to increasing pressure will increase the density of carbon dioxide that the solubility carbon dioxide can be increased to extract peanut skin oil. The other reason is the increase of pressure increased the diffusivity of $\mathrm{SC}-\mathrm{CO}_{2}$ to penetrate the peanut skin surface [31]. Furthermore, the ratio of modifier is also significant parameters to enhance the oil yield of peanut skin. This is due to ethanol as modifier opens the pore of the solute. 
The opened peanut skin cores are easily penetrated by supercritical carbon dioxide to carry out the extract. In addition, the increasing the rate of modifier would increase the diffusivity and solubility of the target compound in $\mathrm{SC}-\mathrm{CO}_{2}$ [32]. Moreover, the temperature is not a significant effect in the extraction of peanut skin oil due to the thermo-labile effect, where temperature effect gives the unstable concentration of bioactive compounds. One of the significant reason is the degradation process of bioactive compounds [8].

In this study, there are five development models which are Lewis model, Page model, Peleg model, Henderson and Pabis Model, and Avhad and Macetti model. Figure 2 to 4 show the five models correlated the experimental data. The average of coefficients of determination $\left(R^{2}\right)$ and the lowest average of coefficients of determination (\%AARD) are the most suitable statistical method to determine the fitting between of mathematical model and experimental data, where the fitted parameters are shown in Table 1.

Five correlations were succeeded to correlate peanut skin oil data under pressure ranging from $10 \mathrm{MPa}$ to $30 \mathrm{MPa}$, the temperature of $40^{\circ} \mathrm{C}$ to $70{ }^{\circ} \mathrm{C}$, and rate of modifier $0.075 \mathrm{~mL} / \mathrm{min}$ to $0.225 \mathrm{~mL} / \mathrm{min}$. Correlation kinetic of peanut skin oil with modified models of Lewis, Page, Peleg, Henderson-Pabis, and Avhad and Macetti with average AARD (\%) of 9.52\%, 4.67\%, 6.87\%, 0.26\%, and 0.24\%. Development of Avhad and Macetti equation has been successfully correlating the kinetic peanut skin oil data with the lowest AARD (\%). Moreover, the modified Lewis model gives the highest AARD (\%), indicating that the modified Lewis model has failed to correlate the kinetic of peanut skin oil compared with another kinetic model.

\section{Lewis model fitted the PSOR data}

Table 1 shows that the coefficient $k_{l}$ as the Lewis adjustable parameters ranged from 0.003 to 0.044 . Lewis model has the highest average error (9.52\%) and the highest error compared with other models. The one adjustable parameter is not enough to correlate the mass transfer of peanut skin oil. Furthermore, the coefficient $k_{l}$ of Lewis model represents the mass transfer process between the peanut skin oil and modified $\mathrm{SC}-\mathrm{CO}_{2}$. Based on the fitting model, increasing pressure and rate of modifier increases the coefficient $k_{l}$ represents the increasing of pressure and ratio of modifier will increase the mass-transfer process. The increasing of pressure will increase density; therefore, it increased the oil yield recovery. the contradictive condition was occurred in the increasing temperature where it did not increase the coefficient $k_{l}$. Thus, the temperature did not affect to enhance the mass transfer process. Increasing of temperature decrease the density of supercritical carbon dioxide [33]. Therefore, the solvation power, $k_{l}$ was decreased.

\section{Henderson-Pabis (H-P) model fitted the PSOR data}

Henderson-Pabis (H-P) model is a development model from the Lewis model with addition of one adjustable parameter. Hence, addition of one adjustable parameter will reduce the error of the model. It significantly shows that the error of $\mathrm{H}-\mathrm{P}$ model is lower than the Lewis model $(0.26 \%<9.52 \%)$. Therefore, the $\mathrm{H}-\mathrm{P}$ model gave a better correlation between the model and experimental data to describe the behaviour of peanut skin oil extraction. However, Figure 3(a2) shows the H-P model failed to fitted the experimental data compared with the Lewis model. The condition of $20 \mathrm{MPa}, 50{ }^{\circ} \mathrm{C}$ and $5 \%$ ratio of modifier showed the addition of one adjustable parameter was not suitable as shown in Table 1. As similar to the Lewis model, the coefficient $k_{h}$ represents the mass transfer process. The coefficient $k_{h}$ was the adjustable parameter ranged from 0.52 to 13.27 in the recovery of peanut skin oil. The increasing coefficient of $\mathrm{k}_{\mathrm{h}}$ was caused by increasing of pressure and ratio of modifier condition. This result and trend are similar with the Lewis model where pressure and rate of modifier were the significant effect to enhance the recovery of extract. The effect of increasing of density will increase the solvation power $\left(\mathrm{k}_{\mathrm{h}}\right)$, thus the oil yield recovery is enhanced [34]. 


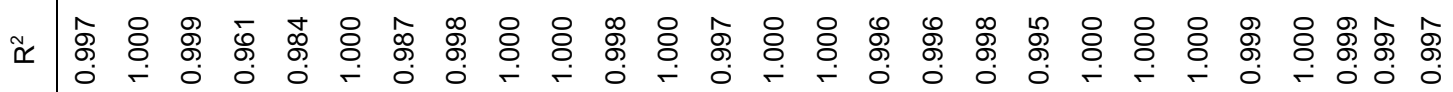

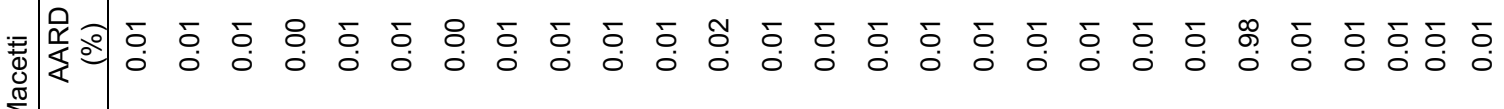

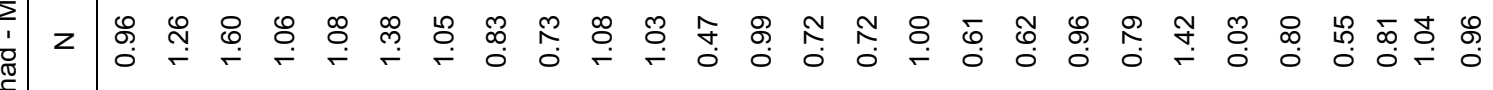

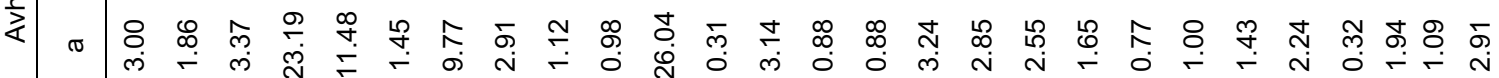
₹ ๘

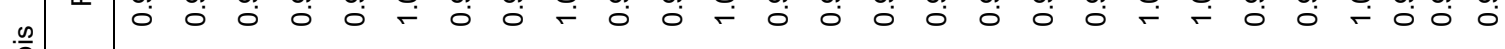

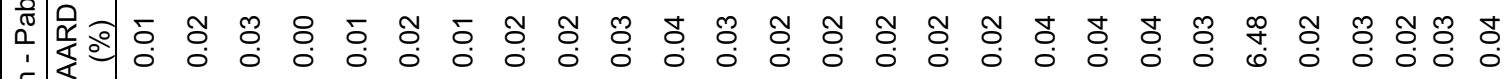
๘

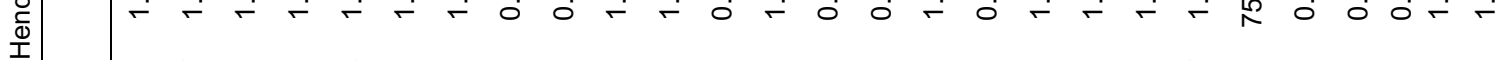
₹

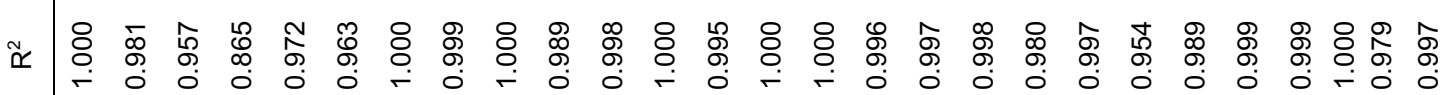

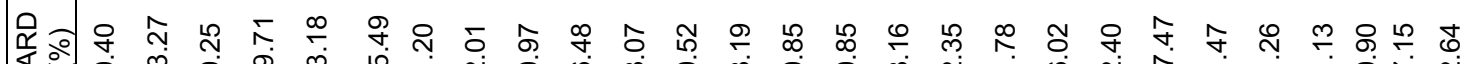

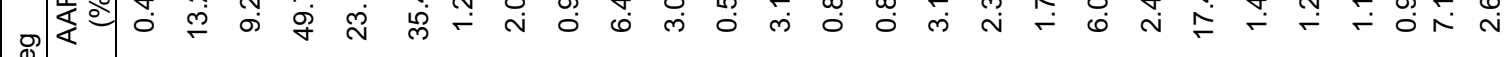
$\frac{\grave{\Phi}}{\Omega}$

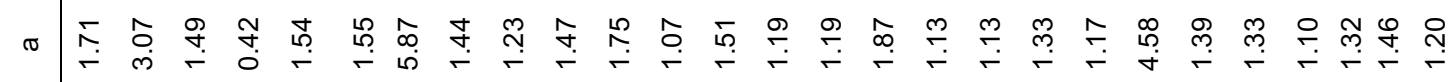
$2 \stackrel{0}{0}$

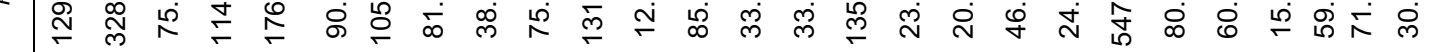

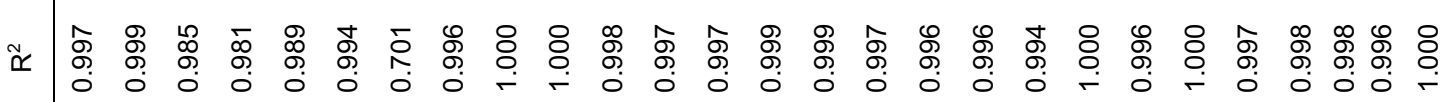
荙

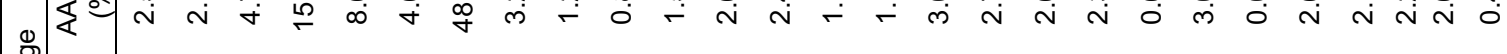
$\stackrel{\mathbb{2}}{\circ}$

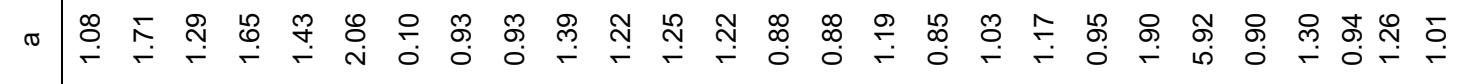
« \& \& 人

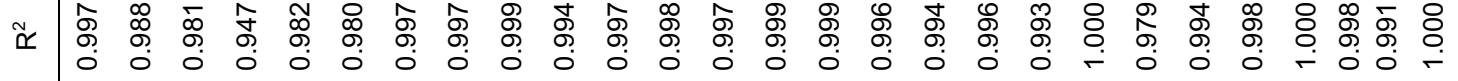

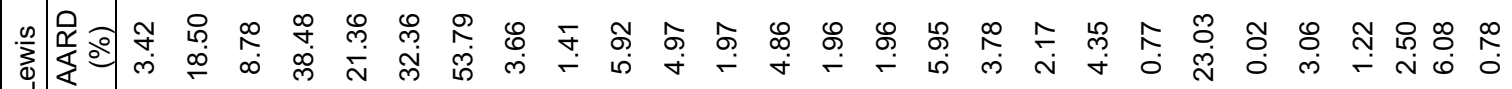
₹

흥

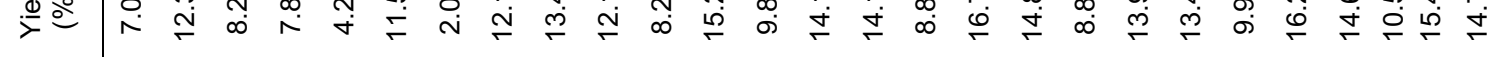

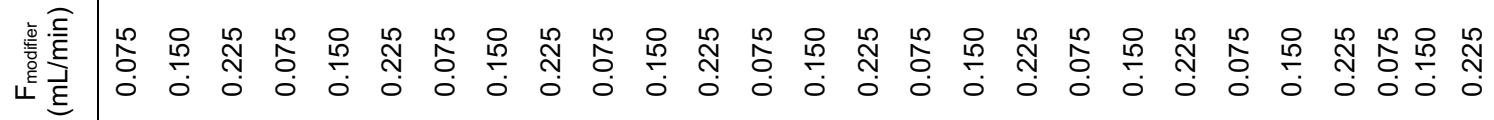

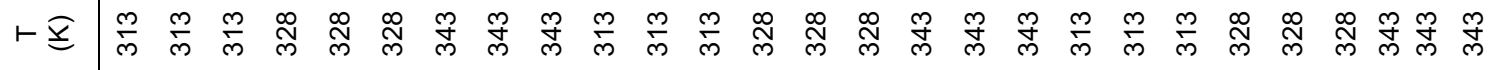

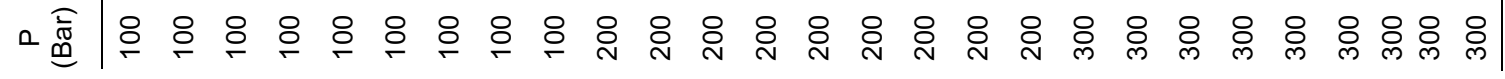




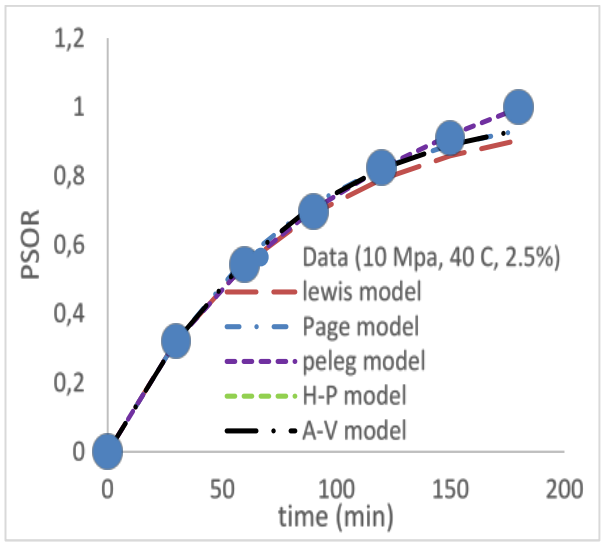

(a1)

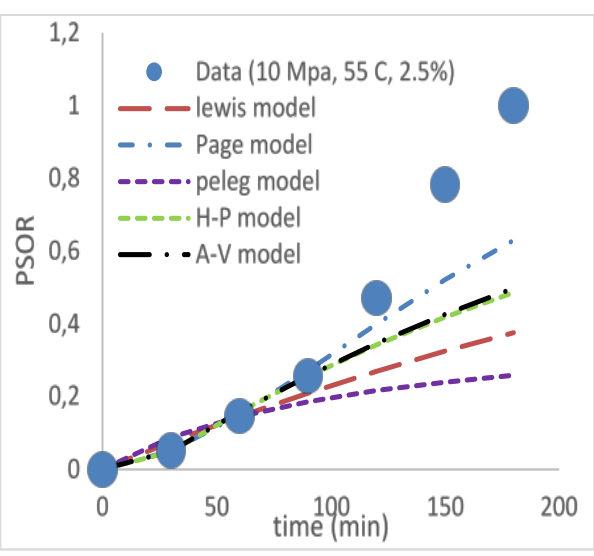

(b1)

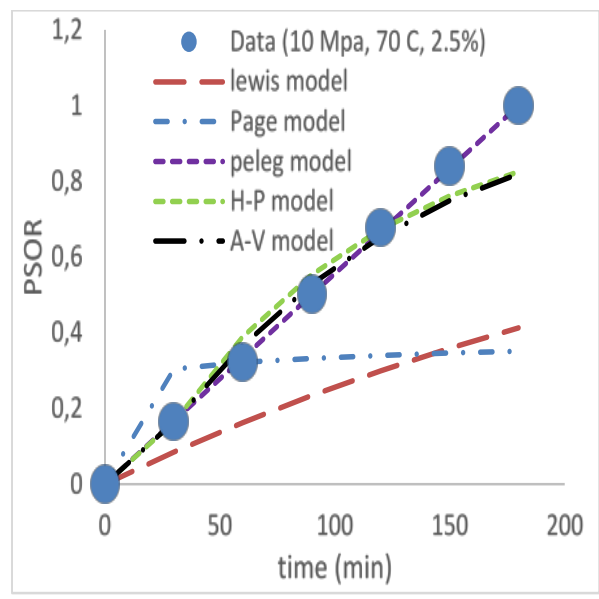

(c1)

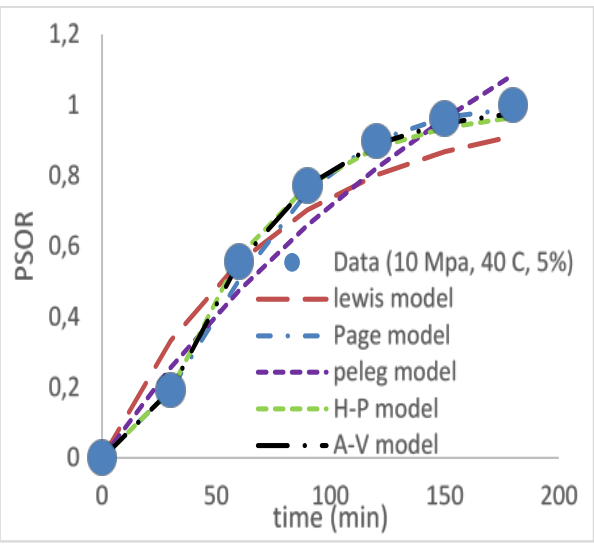

(a2)

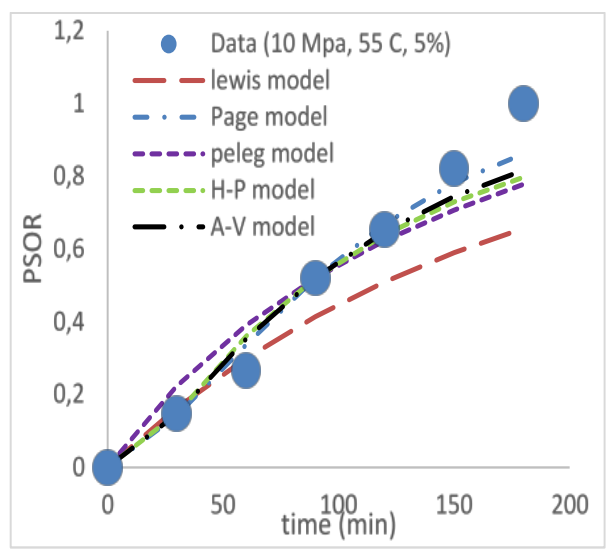

(b2)

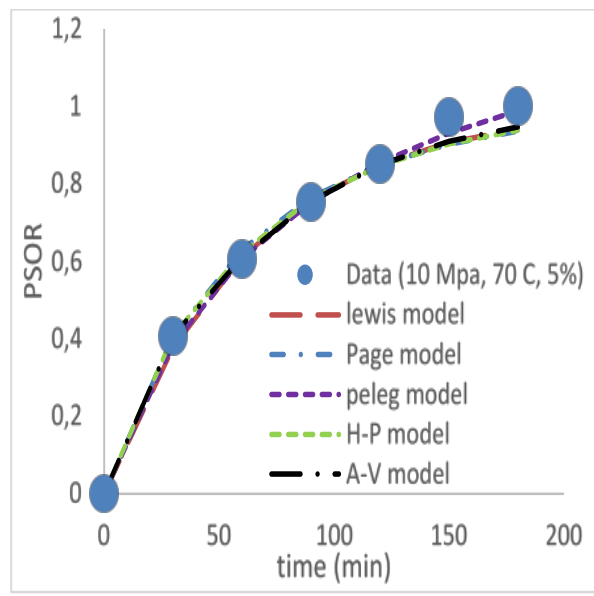

(c2)

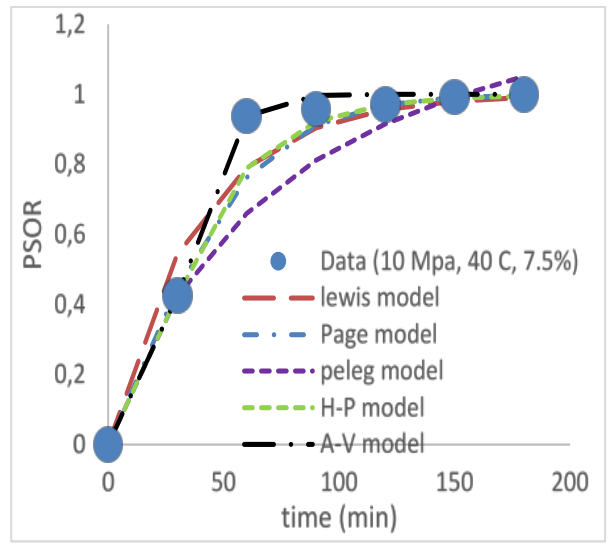

(a3)

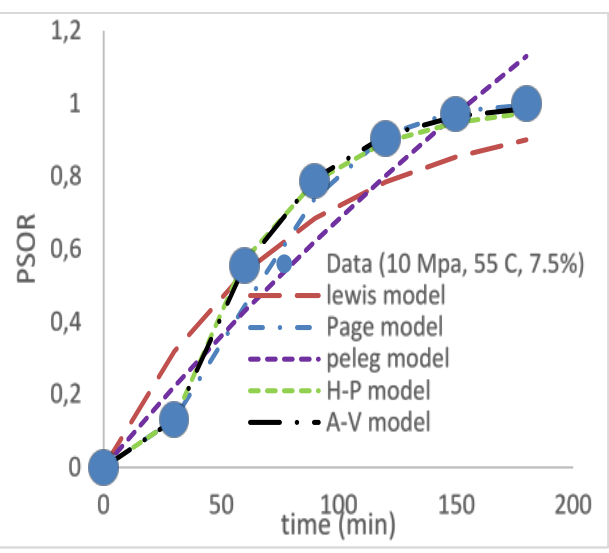

(b3)

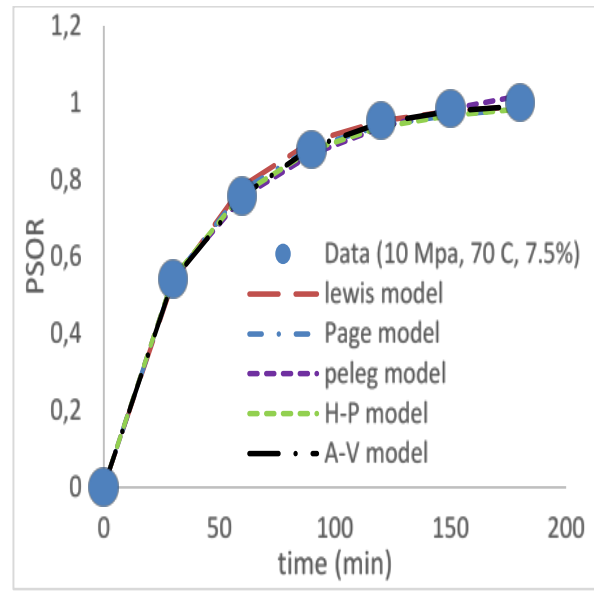

(c3)

Figure 2 Comparison of development between models and experimental data from peanut skin oil at constant pressure 10 MPa and various temperature a) $40^{\circ} \mathrm{C}$, (b) $50^{\circ} \mathrm{C}$, (c) $70^{\circ} \mathrm{C}$ with various ratio of modifier ethanol (1) $2.5 \%$, (2) $5 \%$, (3) $7.5 \%$ 


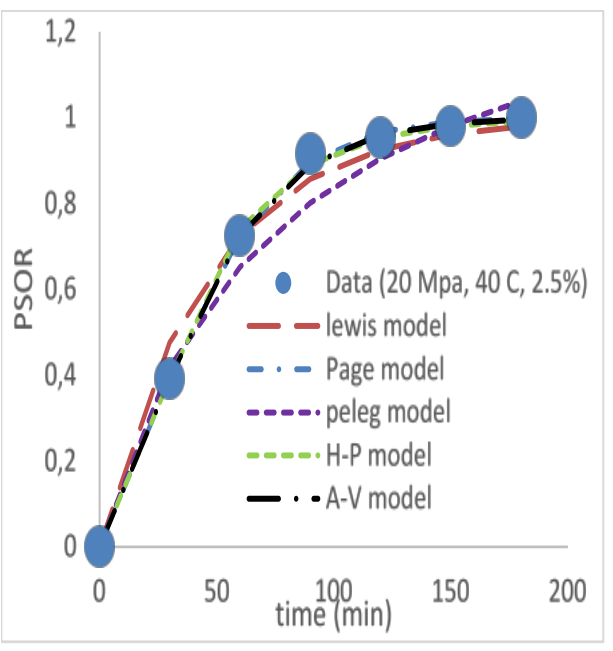

(al)

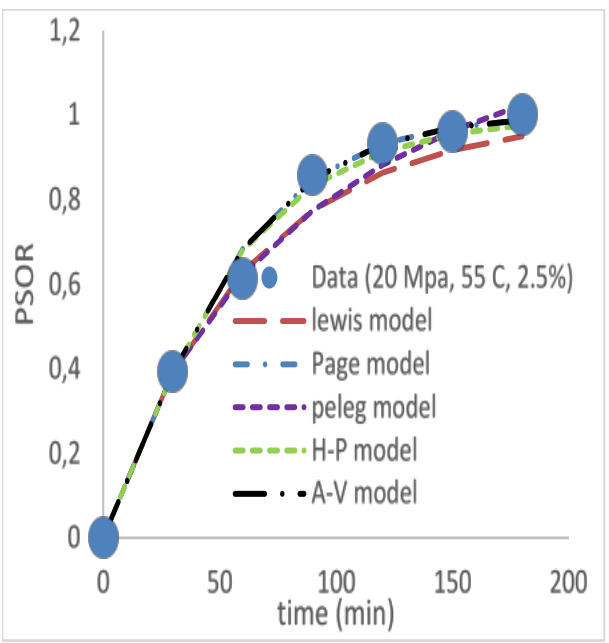

(b1)

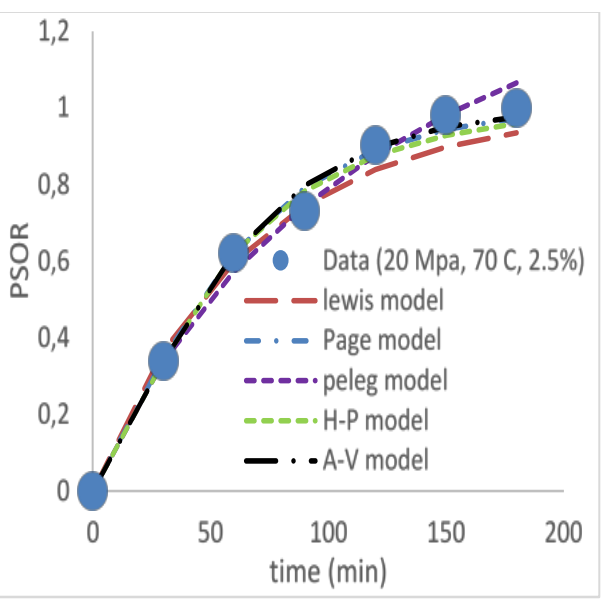

(c1)

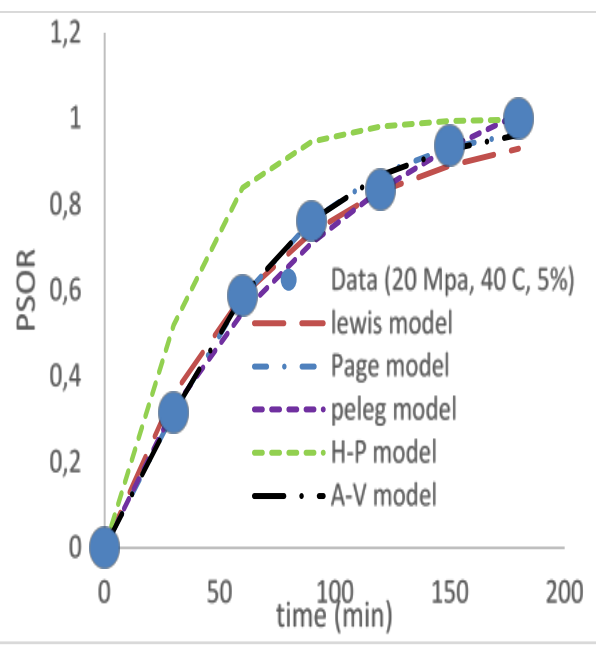

(a2)

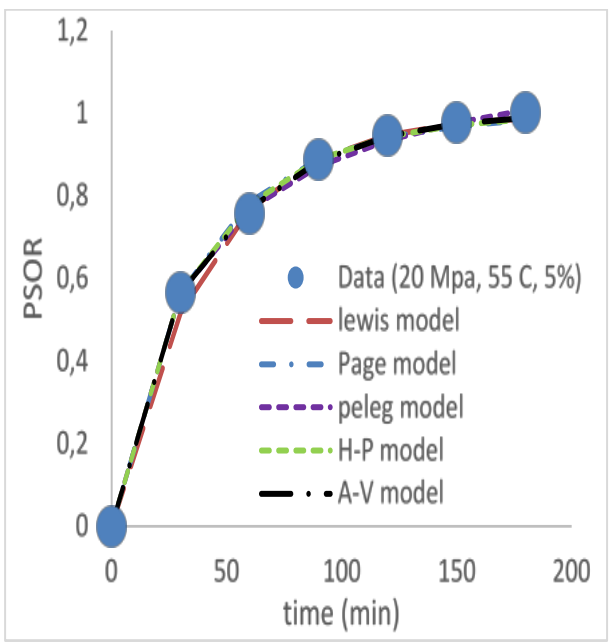

(b2)

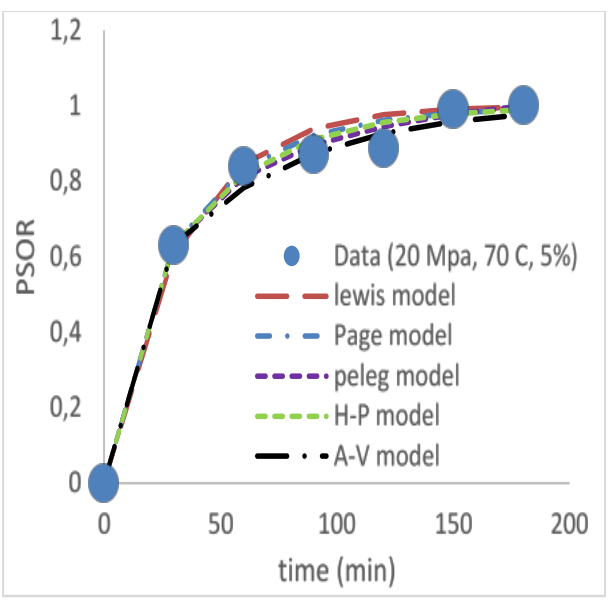

(c2)

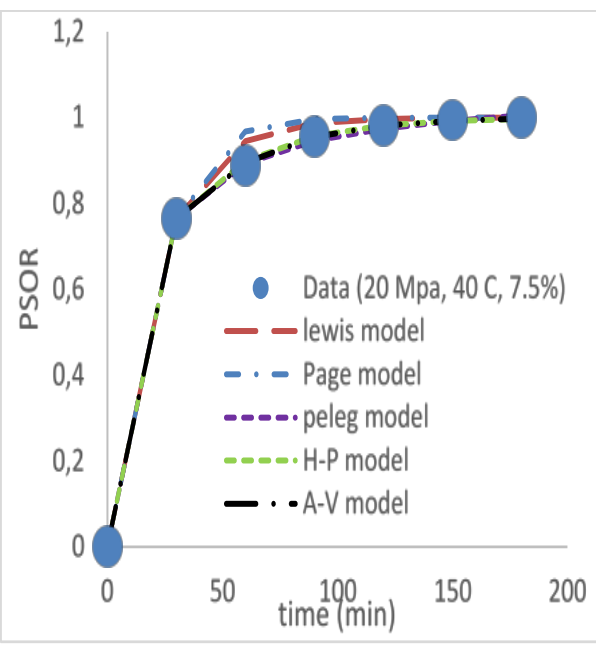

(a3)

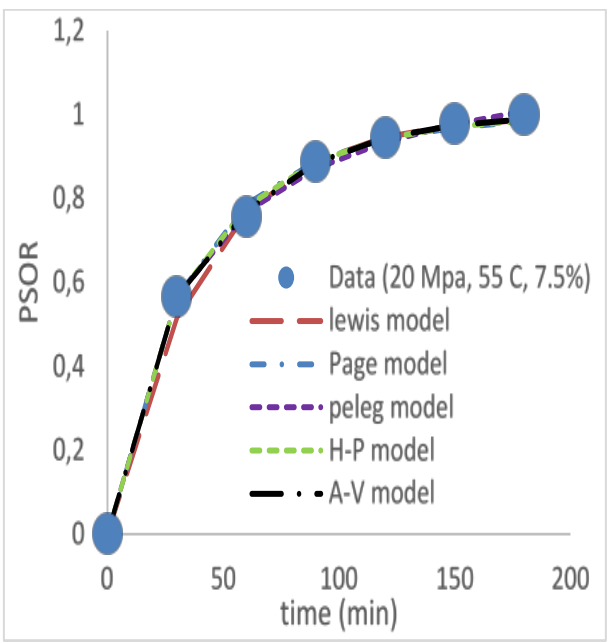

(b3)

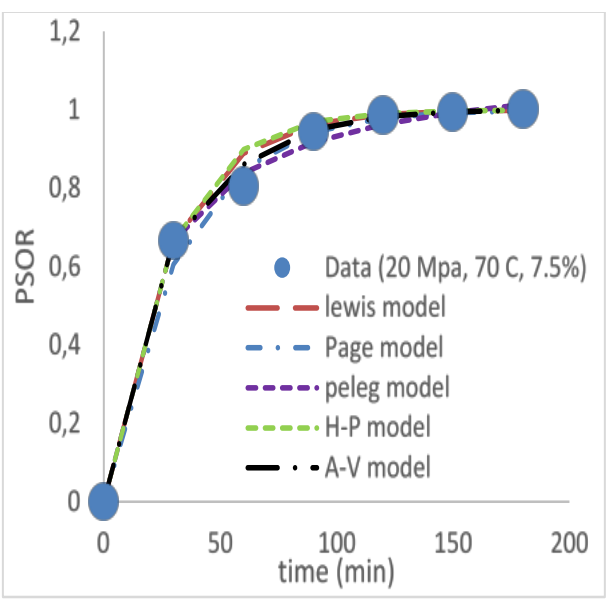

(c3)

Figure 3 Comparison of development between models and experimental data from peanut skin oil at constant pressure 20 MPa and various temperature a) $40^{\circ} \mathrm{C}$, (b) $50^{\circ} \mathrm{C}$, (c) $70^{\circ} \mathrm{C}$ with various ratio of modifier ethanol (1) $2.5 \%$, (2) $5 \%$, (3) $7.5 \%$ 


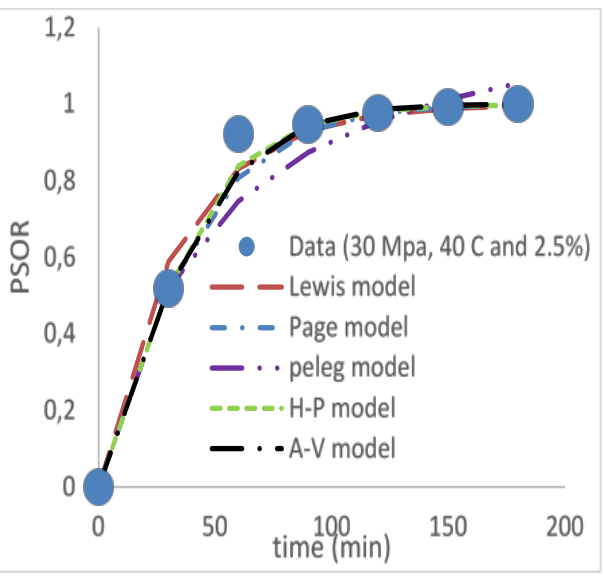

(a)

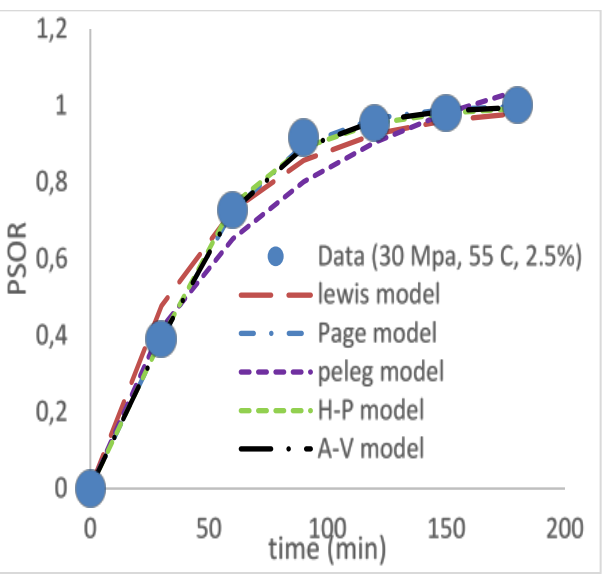

(b1)

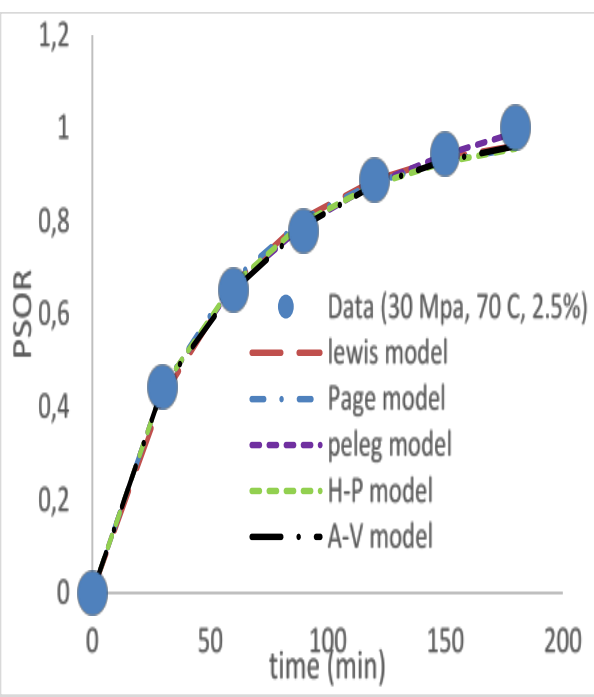

(cl)

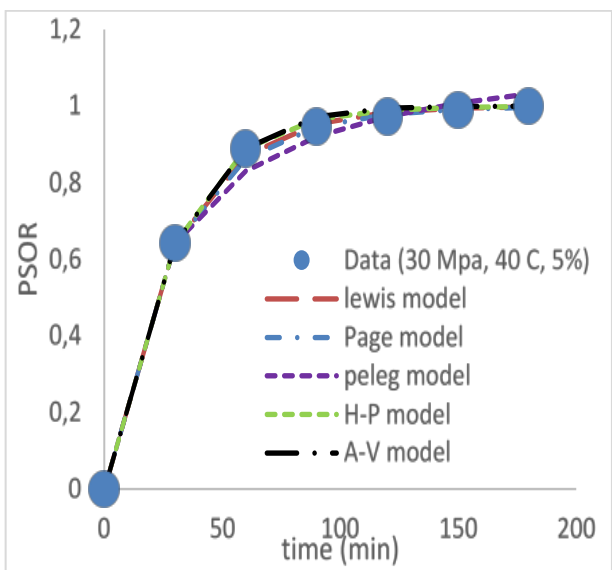

(a2)

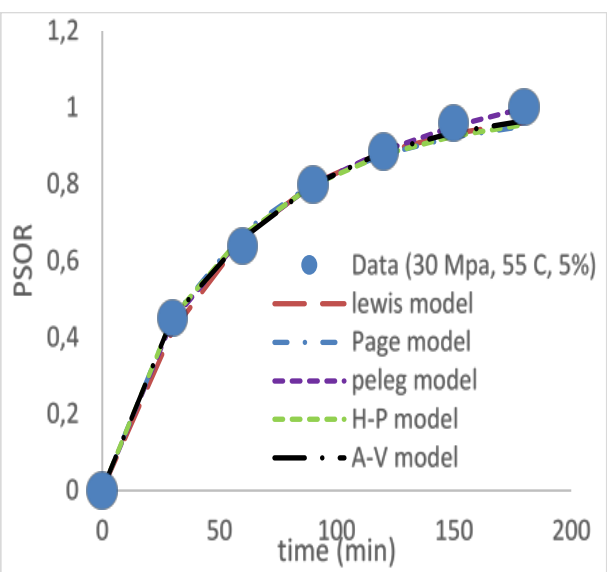

(b2)

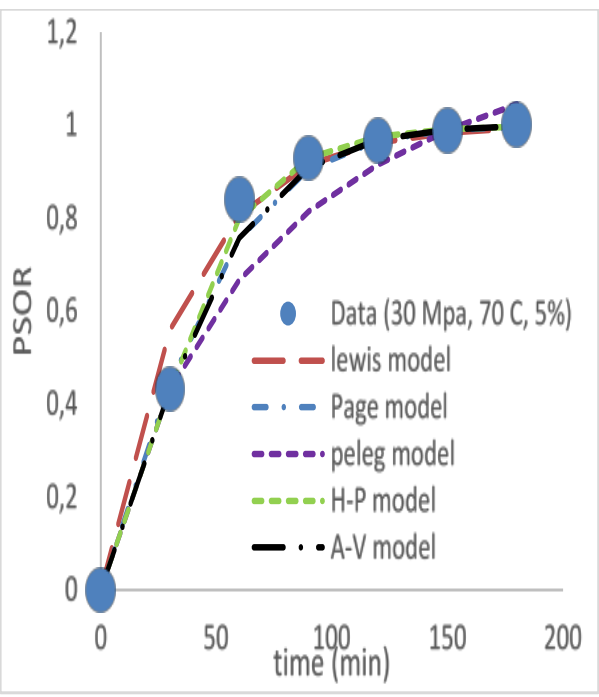

(c2)

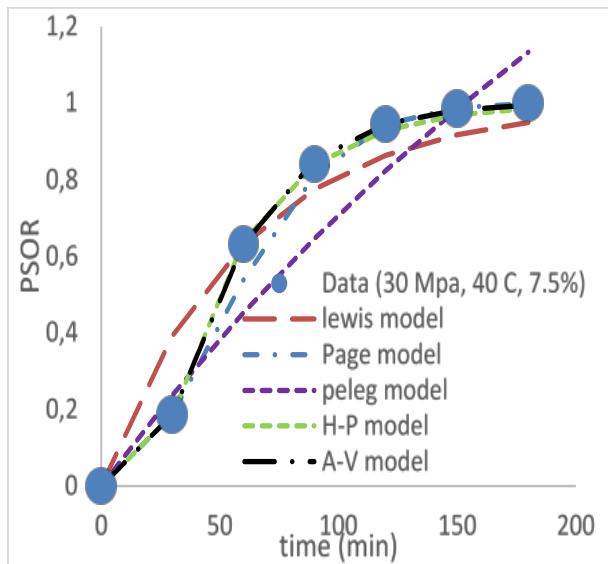

(a3)

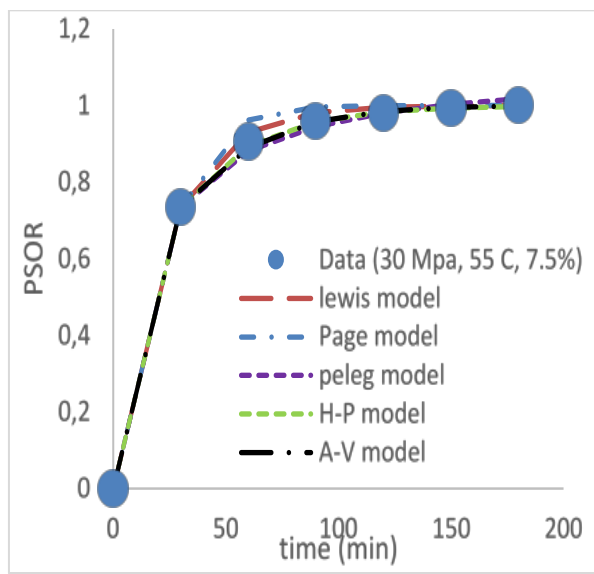

(b3)

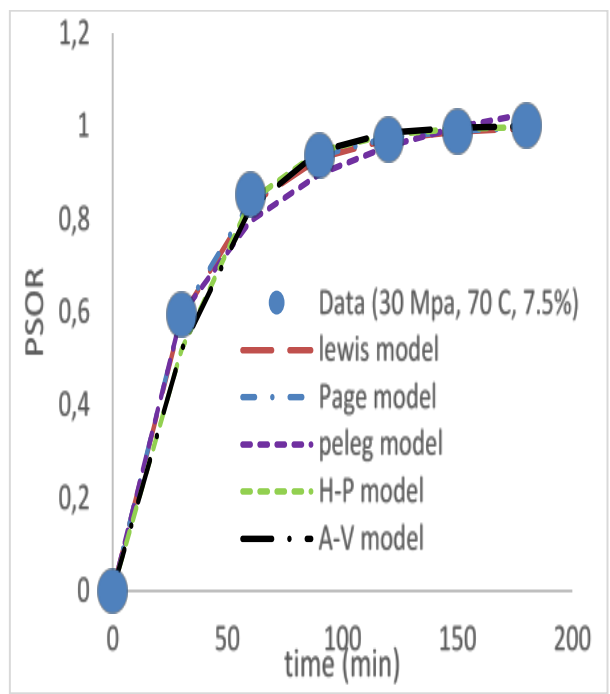

(c3)

Figure 4 Comparison of development between models and experimental data from peanut skin oil at constant pressure 20 MPa and various temperature a) $40^{\circ} \mathrm{C}$, (b) $50^{\circ} \mathrm{C}$, (c) $70^{\circ} \mathrm{C}$ with various ratio of modifier ethanol (1) $2.5 \%$, (2) $5 \%$, (3) $7.5 \%$ 


\section{Page model fitted the PSOR data}

Page model is an improvement model from the Lewis model with addition one adjustable parameter. The addition one adjustable parameter reduced the error of the model to fit the experimental data. The error of the Page model is lower than the Lewis model as the established model $(4.67 \%<9.52 \%)$. The coefficient $k_{p}$ represents the solvation power of mixture solvents (supercritical carbon dioxide and ethanol). The coefficient $\mathrm{k}_{\mathrm{p}}$ ranges was 0.0001 to 0.2578 in the extraction of peanut skin as shown in Table 1. The result of the model shows that increasing the rate of modifier will increase the solvation power $\left(\mathrm{k}_{\mathrm{p}}\right)$ of the solvent. Increasing of modifier rate enhance the polarity of mixture solvents. Most of bioactive compounds in the peanut skin is polar compounds [6], thus increasing of modifier is significant to enhance the peanut skin oil recovery.

\section{Avhad and Macetti (A-M) model fitted the PSOR data}

Avhad and Macetti (A-M) model is a development model from the Lewis model, Page model and Henderson and Pabis Model. The development is the addition of two adjustable parameters which are the coefficient $\mathrm{a}$ and $\mathrm{N}$. The three adjustable parameters gave the best result in the fitting of peanut skin oil extraction. The average of A-M error is lower than $\mathrm{H}-\mathrm{P}$ model and Lewis model $(0.04 \%<0.26 \%<$ $9.52 \%$ ) as shown in Table 2. Hence, the addition of two adjustable parameters is effective and efficient to fit the mass transfer, but the model was difficult to fit the data due to many adjustable parameters. Similar to Lewis and $\mathrm{H}-\mathrm{P}$ model, the coefficient $\mathrm{k}_{\mathrm{a}}$ represents the mass transfer process or solvation power of modified $\mathrm{SC}-\mathrm{CO}_{2}$. The coefficient $\mathrm{k}_{\mathrm{a}}$ ranged from 0.01 to 6.48 . The results of this model gave similar trends with Lewis and Henderson-Pabis model where increasing of pressure increased the solvation power of solvent $\left(\mathrm{k}_{\mathrm{a}}\right)$. Based on the fitting model, the low pressure is not a suitable condition to obtain high mass transfer $\left(\mathrm{k}_{\mathrm{a}}\right)$. This is because low pressure gave penetration power of the solvent to penetrate the raw material $[35,36]$.

\section{Peleg model fitted the PSOR data}

Peleg model is usually used to determine the moisture sorption process in the raw material [21]. The moisture sorption curve is similar to supercritical fluid extraction. Hence, the Peleg model can be used to determine the mass transfer of SC- $\mathrm{CO}_{2}$ extraction. Although, the equation of Peleg model is different with Lewis, Page, Henderson-Pabis and Avhad Macetti models that used the exponential equation to describe the extraction behaviours, the Peleg model has successfully fitted the experimental data with error $6.87 \%$. Furthermore, the coefficient $\mathrm{k}_{\mathrm{g}}$ represents the solvation power of mixture solvents (supercritical carbon dioxide and ethanol). Increasing the coefficient $\mathrm{k}_{\mathrm{g}}$ enhance the mass transfer process between the solvent and the solute. The coefficient $\mathrm{k}_{\mathrm{g}}$ ranges were 15.05 to 547.68 as shown in Table 1. The Peleg model has successfully describe the mass transfer of gallic acid and caffeine from representative white teas [24] and polysaccharides from mushroom [26]. However, the coefficient $\mathrm{k}_{\mathrm{g}}$ in this study could not describe the mass transfer of peanut skin oil due to the inconsistent number of the coefficient $\mathrm{k}_{\mathrm{g}}$.

\section{Comparison Lewis, Page, Henderson-Pabis and Avhad Macetti models results to correlate the peanut skin oil recovery}

The Lewis, Page, Henderson-Pabis and Avhad Macetti models could be used as alternative model to describe the mass transfer model of peanut skin oil due to the low percentage of the model. Furthermore, the advantage of using a drying model as alternative models was easy for the model to fit the experimental data. This is due to less adjustable parameters. Other kinetic models have many adjustable parameters to describe the mass transfer model. However, the Peleg model could not be applied in this study to describe the solvation power of mixture solvents due to the inconsistency of the coefficient $\mathrm{k}_{\mathrm{p}}$. 
Table 2 Comparison between Lewis model, Page model, Peleg model, Henderson and Pabis Model and Avhad and Macetti model

\begin{tabular}{cccc}
\hline No. & Model & \%AARD & $\mathrm{R}^{2}$ \\
\hline 1 & Lewis & 9.52 & 0.982 \\
2 & Page & 4.67 & 0.985 \\
3 & Peleg & 6.87 & 0.983 \\
4 & Henderson and Pabis & 0.26 & 0.994 \\
5 & Avhad and Macetti & 0.04 & 0.996 \\
\hline
\end{tabular}

\section{Conclusions}

Application of drying model in modified supercritical carbon dioxide extraction to determine the mass transfer process were measured at a pressure of $10 \mathrm{MPa}$ to $30 \mathrm{MPa}$, temperature of $40^{\circ} \mathrm{C}$ to $70{ }^{\circ} \mathrm{C}$, and rate of modifier $0.075 \mathrm{~mL} / \mathrm{min}$ to $0.225 \mathrm{~mL} / \mathrm{min}$. The drying models (Lewis, Page, Peleg, Henderson Pabis and Avhad - Macetti models) were found to correlate with peanut skin experimental data. The resulting values average of AARD $(\%)$ and coefficient of determination $\left(R^{2}\right)$ were Lewis model $(9.52 \%$ and 0.982 ), Page model (4.67\% and 0.985$)$, Peleg model (6.87\% and 0.983$)$, Henderson and Pabis model $(0.26 \%$ and 0.994$)$, and Avhad-Macetti model ( $0.04 \%$ and 0.996$)$. Therefore, modification of Avhad-Macetti model gives the lowest AARD (\%) and the coefficient of determination compared with other models. This is because Avhad-Macetti has more adjustable parameters such as three adjustable parameters compared with other modification models. Furthermore, the drying model can be applied as mass transfer model. The Peleg model has the lowest error and highest coefficient of determination, $\mathrm{R}^{2}$, the models are difficult to determine the mass transfer process on the extraction of peanut skin oil. The result of five models shows that the effect of pressure and ratio of modifier enhance the mass transfer of the extraction but the effect of temperature was not significant to encourage the yield and mass transfer of peanut skin oil.

\section{Data availability}

The data that support the findings of this study are available from the corresponding author, upon reasonable request.

\section{Conflicts of interest}

The authors declare that there is no conflict of interest regarding the publication of this paper."

\section{Funding statement}

We also would like to thank the Ministry of Education Malaysia for allocating research grants to UTM Iconic Grant (Q.J130000.4351.09G56) to support this work.

\section{Acknowledgement}

The authors acknowledged the Centre of Lipid Engineering and Applied Research (CLEAR), Universiti Teknologi Malaysia (UTM) for providing research facilities to conduct this study.

\section{References}

[1] Hoang, V.H., P. Apoštolová, J. Dostálová, F. Pudil, and J. Pokorný. Antioxidant activity of peanut skin extracts from conventional and high-oleic peanuts. Antioxidant activity of peanut skin extracts from conventional and high-oleic peanuts, vol. 26, no. 6 , pp. 447-457, 2008. 
[2] Zhongdong, L., W. Guohua, G. Yunchang, and J.F. Kennedy. Image study of pectin extraction from orange skin assisted by microwave. Image study of pectin extraction from orange skin assisted by microwave, vol. 64 , no. 4, pp. 548-552, 2006.

[3] Putra, N.R., M.A.C. Yunus, M.S.H. Ruslan, Z. Idham, and F.N. Idrus. Comparison extraction of peanut skin between $\mathrm{CO}_{2}$ supercritical fluid extraction and soxhlet extraction in term of oil yield and catechin. Comparison extraction of peanut skin between $\mathrm{CO}_{2}$ supercritical fluid extraction and soxhlet extraction in term of oil yield and catechin, vol. 26, no. 2, pp., 2018.

[4] Putra, N.R., M.A. Che Yunus, and S. Machmudah. Solubility model of arachis hypogea skin oil by modified supercritical carbon dioxide, vol. 54, no. 5, pp. 731-740, 2019.

[5] Putra, N.R., M.A. Che Yunus, and S. Machmudah Solubility model of arachis hypogea skin oil by modified supercritical carbon dioxide, vol., no., pp. 1-10, 2018.

[6] Putra, N.R., D.N. Rizkiyah, A.S. Zaini, S. Machmudah, and M.A.C. Yunus. Solubility of catechin and epicatechin from Arachis Hypogea skins wastes by using supercritical carbon dioxide-ethanol and its optimization. vol., no., pp. 1-8, 2021.

[7] Putra, N.R., D.N. Rizkiyah, S. Machmudah, L.M. Shalleh, and M.A. Che Yunus. Recovery and solubility of flavonoid and phenolic contents from Arachis Hypogea in supercritical carbon dioxide assisted by ethanol as cosolvent, vol., no., pp. e14768.

[8] Zeković, Z., O. Bera, S. Đurović, and B. Pavlić. Supercritical fluid extraction of coriander seeds: Kinetics modelling and ANN optimization, vol. 125, no., pp. 88-95, 2017.

[9] Machmudah, S., A. Shotipruk, M. Goto, M. Sasaki, and T. Hirose. Extraction of astaxanthin from Haematococcus p luvialis using supercritical CO2 and ethanol as entrainer, vol. 45, no. 10, pp. 3652-3657, 2006.

[10] Putra, N.R., A.G. Wibobo, S. Machmudah, and S. Winardi. Recovery of valuable compounds from palm-pressed fiber by using supercritical $\mathrm{CO}_{2}$ assisted by ethanol: modeling and optimization, vol., no., pp. 1-14, 2019.

[11] Jacobsen, D. and K.E. McMartin. Methanol and ethylene glycol poisonings. Methanol and ethylene glycol poisonings, vol. 1, no. 5, pp. 309-334, 1986.

[12] Corzzini, S.C.S., H.D.F.Q. Barros, R. Grimaldi, and F.A. Cabral. Extraction of edible avocado oil using supercritical CO2 and a CO 2 /ethanol mixture as solvents, vol. 194, no., pp. 40-45, 2017.

[13] Yunus, M.C., N. Arsad, S. Zhari, Z. Idham, S. Setapar, and A. Mustapha. Effect of supercritical carbon dioxide condition on oil yield and solubility of Pithecellobium Jiringan Prain seeds, vol. 60, no., pp. 45-50, 2013.

[14] Shi, J., C. Yi, S.J. Xue, Y. Jiang, Y. Ma, and D. Li. Effects of modifiers on the profile of lycopene extracted from tomato skins by supercritical $\mathrm{CO}_{2}$, vol. 93, no. 4, pp. 431-436, 2009.

[15] Salgın, U., S. Salgın, D.D. Ekici, and G. Uludal. Oil recovery in rosehip seeds from food plant waste products using supercritical co2 extraction, vol. 118, no., pp. 194-202, 2016.

[16] Murthy, T.P.K. and B. Manohar. Modelling solubility of phenolics of mango ginger extract in supercritical carbon dioxide using equation of state and empirical models, vol. 52, no. 9, pp. 5557-5567, 2015.

[17] Danlami, J.M., M.A.A. Zaini, A. Arsad, and M.A.C. Yunus. Solubility assessment of castor (I oil in supercritical $\mathrm{CO}_{2}$ at different temperatures and pressures under dynamic conditions, vol. 76, no., pp. 34-40, 2015.

[18] Goto, M., J. Smith, and B.J. McCoy. Parabolic profile approximation (linear driving-force model) for chemical reactions. Parabolic profile approximation (linear driving-force model) for chemical reactions, vol. 45, no. 2, pp. 443-448, 1990.

[19] Lewis, W.K. The rate of drying of solid materials. The rate of drying of solid materials, vol. 13, no. 5, pp. 427432, 1921.

[20] Diamante, L.M. and P.A. Munro Mathematical modelling of the thin layer solar drying of sweet potato slices, vol. 51, no. 4, pp. 271-276, 1993.

[21] Peleg, m. An empirical model for the description of moisture sorption curves. An empirical model for the description of moisture sorption curves, vol. 53, no. 4, pp. 1216-1217, 1988.

[22] Pabis, S. and S. Henderson Grain drying theory. II. A critical analysis of the drying curve for shelled maize. Grain drying theory. II. A critical analysis of the drying curve for shelled maize, vol. 6, no. 4, pp. 272-277, 1961.

[23] Avhad, M. and J. Marchetti Mathematical modelling of the drying kinetics of Hass avocado seeds, vol. 91, no., pp. 76-87, 2016.

[24] Lin, C., G. Xia, and S. Liu Modeling and comparison of extraction kinetics of 8 catechins, gallic acid and caffeine from representative white teas, vol. 83, no., pp. 1-9, 2017.

[25] Paternina Contreras, A., J. Salcedo Mendoza, K. Contreras Lozano, and M. Garcia Paternina Characterization and desorption isotherm modeling of cassava bagasse (Manihot esculenta Crantz), vol. 69, no. 3-4, pp., 2017.

[26] Aguiló-Aguayo, I., J. Walton, I. Viñas, and B.K. Tiwari Ultrasound assisted extraction of polysaccharides from mushroom by-products, vol. 77, no., pp. 92-99, 2017.

[27] Charpe, T. and V. Rathod kinetics of ultrasound assisted extraction of wedelolactone from Eclipta alba, vol. 33 , no. 4, pp. 1003-1010, 2016.

[28] Aitchison, J. The statistical analysis of compositional data. The statistical analysis of compositional data, vol., no., pp., 1986

[29] Taylor, J., Introduction to error analysis, the study of uncertainties in physical measurements. 1997.

[30] Putra, N.R., Z.B. Idham, S. Machmudah, M.S.H.b. Ruslan, and M.A. Che Yunus Extraction of peanut skin oil by modified supercritical carbon dioxide: Empirical modelling and optimization, vol., no., pp. 1-9, 2018.

[31] Putra, N.R., A.H.A. Aziz, Z. Idham, M.S.H. Ruslan, and M.A.C. Yunus. Diffusivity optimization of supercritical carbon dioxide extraction with co-solvent-ethanol from peanut skin, vol. 14, no. 1, pp., 2018.

[32] Cornelio-Santiago, H.P., C.B. Gonçalves, N.A. de Oliveira, and A.L. de Oliveira. Supercritical CO2 extraction of oil from green coffee beans: Solubility, triacylglycerol composition, thermophysical properties and thermodynamic modelling, vol. 128, no., pp. 386-394, 2017.

[33] Idham, Z., A.S. Zaini, N.R. Putra, N.M. Rusli, N.S. Mahat, L.N. Yian, and M.A.C. Yunus. Effect of flow rate, particle size and modifier ratio on the supercritical fluid extraction of anthocyanins from Hibiscus sabdariffa $(L)$. in IOP Conference Series: Materials Science and Engineering. 2020. IOP Publishing. 
[34] Mohd-Nasir, H., N.R. Putra, S.C. Chuo, N.M. Daud, N. Bakeri, M.S.H. Ruslan, S.H. Mohd-Setapar, A. Ahmad, and L. Md Salleh. optimization of the supercritical carbon dioxide extraction of quercus infectoria galls extracts and its bioactivities, vol., no., pp. e15156.

[35] Hatami, T., M.A.A. Meireles, and O.N. Ciftci. Supercritical carbon dioxide extraction of lycopene from tomato processing by-products: Mathematical modeling and optimization, vol. 241, no., pp. 18-25, 2019.

[36] de Andrade Lima, M., D. Charalampopoulos, and A. Chatzifragkou Optimisation and modelling of supercritical $\mathrm{CO}_{2}$ extraction process of carotenoids from carrot peels, vol. 133, no., pp. 94-102, 2018. 